\title{
Por que um dicionário é um texto?
}

Marlene Gonçalves Mattes ${ }^{a}$

Félix Valentín Bugueño Miranda ${ }^{b}$

\section{Resumo}

Os dicionários apresentam a particularidade de parecerem livros sem, aparentemente, possuírem as mesmas características de outras classes de livros, como as publicações científicas e os romances. O presente trabalho tem por objetivo demonstrar, à luz de uma teoria linguística, a condição de texto dos dicionários.

Palavras-chave: dicionário; linguística de texto; tipo; gênero 


\section{Introdução}

O dicionário apresenta uma série de particularidades. Por um lado, enquanto objeto ${ }^{1}$ (físico), possui uma semelhança de forma com outros objetos (físicos) que empregam o mesmo sistema semiótico, a linguagem, tais como as obras literárias e as obras acadêmicas. Por essa similitude, caberia afirmar que os dicionários também são textos. Aliás, a similitude parece ser tão evidente, que há obras de referência e obras de ficção caracterizadas pela mesma dimensão, neste caso, pelo tamanho. Destarte, fala-se em edições de bolso de dicionários e de romances, por exemplo. Por outro lado, um dicionário e um guia de telefone se diferenciam claramente das outras obras impressas citadas ad supra, porque a disposição das informações do dicionário e do guia telefônico se faz de acordo com um formalismo, mais especificamente, de acordo com um algoritmo (cf. BUGUEÑO MIRANDA, 2007, para esse conceito). Evidentemente, entre um dicionário e um guia de telefone existe também uma diferença evidente, já que o primeiro fornece informações sobre a própria linguagem (metalinguagem de primeiro nível (cf. BALDINGER, 1977)), enquanto que o segundo oferece informações factuais ${ }^{2}$ as quais vão além da linguagem propriamente dita (endereços, número de telefone, etc.).

As constatações feitas no parágrafo precedente levam a refletir sobre o status do dicionário como objeto organizado

1 Por objeto se entende a matéria ou conteúdo da nossa representação [Gegenstand oder Inhalt unserer Vorstellung], cf. Kirchner et alii. (2013, s.v. Objekt).

2 Informação factual ou informação enciclopédica, segundo Hartmann; James (2001, s.v. encyclopedic information) é aquela informação baseada no conhecimento "das coisas" e que está mais relacionada com a descrição de realidades objetivas [objective realities] que com as palavras que referem ditas realidades. No entanto, Hartmann; James (2001, s.v.) reconhecem também que é difícil traçar um limite claro entre informação factual e enciclopédica. de informações, visto que, ao mesmo tempo em que se pode estabelecer uma relação entre ele e outros objetos análogos como os citados anteriormente, também é possível perceber a natureza sui generis da obra lexicográfica frente a esses objetos.

\section{0 dicionário olhado como texto}

Nos parágrafos precedentes, o dicionário foi caracterizado como um objeto (físico) de formato análogo a uma classe de objetos designada genericamente como livro. Hou (2009, s.v.), por exemplo, define livro como " 1 . coleção de folhas de papel, impressas ou não, cortadas, dobradas e reunidas em cadernos cujos dorsos são unidos por meio de cola, costura, etc. formando um volume que se recobre com capa resistente. 2. livro (acp.1) considerado tb. [sic!] do ponto de vista do seu conteúdo: obra de cunho literário, científico, técnico, documentativo, etc. que 
3 A asserção de Wiegand (1989) é epistemologicamente válida na medida em que se cumpre com a premissa básica de haver alguma experiência "para adquirir os conceitos envolvidos" na proposição formulada (cf. BLACKBURN, 1997, s.v. a priori / a posteriori). Esse a priori, como se verá mais adiante, está dado por uma abordagem fenomenológica.

4 Isto quer dizer a apreensão "das coisas observadas como tais" [die beobachten Sachen als solche], cf. Rehfus (2003, s.v. Phänomenologie). constitui um volume [Segundo as normas de documentação da ABNT e organismos internacionais, é a publicação com mais de 48 páginas, além da capa]".

Na perspectiva extensional que toda paráfrase explanatória possui (cf. BUGUEÑO MIRANDA, 2009 e BUGUEÑO MIRANDA e FARIAS, 2013 para esse conceito) um dicionário pode ser incluído, sem nenhuma dificuldade, na classe dos livros, segundo a paráfrase formulada por Hou (2009, s.v.). De facto, Wiegand (1989, p. 328), ao se referir ao dicionário, "de uma perspectiva textual" [in a textual perspective], distingue na palavra dicionário pelo menos dois significados: o livro como um todo e a lista de palavras [the whole book and the word list], reconhecendo tanto uma estrutura textual do livro como uma estrutura textual das palavras.

Em relação à estrutura textual do livro (= dicionário), Wiegand (1989, p. 330) confere, a priori ${ }^{3}$, o status de texto ao dicionário (mais especificamente ao dicionário geral monolíngue), assumindo que os dicionários "devem ser entendidos como textos de um determinado tipo" [may be understood as texts of a certain type] (ibid). Dando seguimento a sua argumentação, Wiegand (1989, ibid) afirma que os dicionários, como textos, devem ser divididos em "partes componenciais funcionais (ou elementos funcionais)" [they may be segmented into functional components parts (or functional elements)], de acordo com o conhecimento que temos sobre a estrutura dos livros. Essas partes componenciais funcionais correspondem ao título, à tabela de conteúdos, à ficha catalográfica, ao guia de usuário, ao compêndio de noções gramaticais do dicionário [the dictionary Grammar], à lista de palavras, ao apêndice I (expressões idiomáticas vernáculas e estrangeiras) e ao apêndice II (abreviaturas).

A exposição de Wiegand (1989) merece duas reflexões: em primeiro lugar, as suas afirmações, pelo menos parcialmente, partem do princípio a priori de que um dicionário é um texto. O raciocínio que sustenta essa afirmação parece estar baseado em uma perspectiva extensional, a qual perfeitamente poderia ser obtida a partir da "aplicação à realidade", por exemplo, da paráfrase explanatória de texto oferecida por Hou (2009, s.v). Em segundo lugar, e intimamente ligado ao anterior, a aproximação de Wiegand (1989) é eminentemente fenomenológica ${ }^{4}$. A sua 
5 O emprego de axiomas permite definir em termos estritamente formais os constituintes pertinentes para uma dada estrutura parcial do dicionário (cf. BUGUENO MIRANDA, 2007; também BUGUEÑO MIRANDA e ZANATTA, 2010 para a aplicação de princípios axiomáticos na definição da macroestrutura e da medioestrutura de um dicionário).

6 Os componentes indispensáveis (estruturantes) de um dicionário são chamados em Bugueño Miranda (2013a) de constituintes canônicos. Eles são: Macro-, micro- e medioestrutura. Fornari (2008) sentou as bases axiomáticas para incorporar o Front Matter como um membro mais dos componentes canônicos.

7 Isenberg (1987) define tipo de texto como "uma forma específica de texto, descrita e definida no marco de uma tipologia textual" [forma específica de texto, descrita y definida dentro Del marco de uma tipologia textual].

8 Imanência linguística ou linguística interna corresponde à perspectiva de estudos que se preocupa por questões da língua per se, com independência da projeção dos fatos da língua como insumos explanatórios de outros domínios como a psicologia, sociologia, etc. apreensão do objeto se baseia na pura constatação ad oculos, o que é facilmente comprovável caso se considere, por exemplo, que não há ainda um trabalho que defina axiomaticamente ${ }^{5}$ (ou por outro meio) a constituição das partes introdutórias de um dicionário, que, do ponto de vista da teoria metalexicográfica, correspondem ao Front Matter ${ }^{6}$.

É bom frisar que Wiegand (1989), no entanto, no momento de abordar o dicionário de uma perspectiva textual, distingue entre o livro como um todo e a lista de palavras. Essa distinção, à luz das ponderações feitas ad supra, deve ser reexaminada.

\section{O dicionário: da perspectiva fenomenológica à ontológica}

Sem dúvida alguma, o resultado de uma aproximação fenomenológica do dicionário é insatisfatório. Fenomenologicamente também, e como já foi feito, é fácil provar que um dicionário não é um texto parecido com muitos outros textos que, embora apresentem também claras diferenças entre si, são aceitos como textos ainda assim, como é o caso de um manual de ciências e um tratado de estética literária. Em termos teóricos, trata-se de manifestações textuais diferentes pertencentes ao mesmo tipo, como exposto por Isenberg (1987). Assim, por exemplo, as classes "manual de ciências" e "tratado de estética literária" pertencem ao tipo "texto científico"7.

À luz das considerações precedentes, é evidente que é necessário tentar se abordar o problema de uma perspectiva ontológica, mais precisamente, de formalismos linguísticos. Epistemologicamente, não há outra forma de se resolver a questão senão à luz de argumentos de imanência linguística, ou, caso se prefira, de linguística interna ${ }^{8}$ (cf. MLS (2010, s.v. Sprachwissenschaft).

Nessa perspectiva, Frawley (2003) examina o dicionário à luz de pressupostos teórico metodológicos da linguística do texto, mas o foco do trabalho é refletir sobre a gramática textual presente nas paráfrases explanatórias, apresentando uma análise cujo corolário é a necessidade de gerar paráfrases mais elucidativas. Dito em outros termos, as reflexões de Frawler (2003) dizem respeito unicamente a um parâmetro textual, isto é, à coesão. 
9 O que subsume a palavra dicionário corresponde, na verdade, a uma classe extensa de obras de referência sobre uma língua natural que se articulam e se classificam de acordo com uma série de princípios ontológicos da linguagem, tais como semasiologia - onomasiologia; norma real - norma ideal, discursolivre-discurso repetido, etc. Cf. Bugueño Miranda (2014) para uma proposta de classificação de obras lexicográficas.

10 Sobre os dicionários pela imagem na lexicografia alemã, cf. Bugueño Miranda (2008 p. 101-102).

11 Exemplos dessa tradição são DuBldWtb (1995) e VWtbPD (2010) (cf. resenha de BUGUEÑO MIRANDA, 2013b).

12 OhneWtb (1999) está organizado em 16 quadros temáticos.

13 O trocadilho consiste em que Wörterbuch [dicionário] significa ipsis litteris "livro das palavras"; por sua vez, a preposição ohne significa "sem". Destarte, Ohnewörterbuch equivale a dizer "livro das palavras sem palavras".

14 Zwtb (2014) está organizado em 7 quadros temáticos.
Aliás, tanto os trabalhos de Wiegand (1989) como o de Frawler (2003) dizem respeito unicamente a obras lexicográficas gerais de orientação semasiológica ${ }^{9}$. Nesse sentido, é fundamental considerar que a extensa e heterogênea quantidade de obras lexicográficas também constitui um fator a ser considerado no momento de tentar legitimar o dicionário como uma classe de textos. Dito em outros termos, no momento de fazer afirmações sobre a "estrutura textual" (como em WIEGAND, 1989), essas afirmações, além de serem eminentemente fenomenológicas, só seriam válidas se aplicadas a obras gerais de orientação semasiológica. No entanto, em uma tradição lexicográfica extremamente rica como a alemã, por exemplo, existe um genótipo lexicográfico chamado "dicionário pela imagem"10 [Bildwörterbuch $]^{11}$, em que não há praticamente partes introdutórias, tampouco paráfrases explanatórias. Um outro exemplo a ser considerado é uma novidade no mercado lexicográfico (particularmente alemão), para a qual ainda não existe uma denominação específica. Dependendo da editora, é chamado de OhneWörterBuch ${ }^{12}$ (um inteligentíssimo trocadilho, já que, de facto, não há lemas ${ }^{13}$ ) ou Zeigewörterbuch ${ }^{14}$ (uma designação também muito apropriada, pois, tanto quanto no caso anterior, o usuário deve apontar para uma gravura do dicionário a fim de estabelecer uma relação comunicativa mínima). Nessas condições, o reconhecimento do objeto dicionário como um texto se converte em uma tarefa complexa.

\section{O dicionário na perspectiva específica do texto}

A primeira constatação que se faz sobre o questionamento proposto neste estudo é fenomenológica, ou seja, dicionário também é um "livro", logo também é um texto.

Vários caminhos na Linguística ofereceriam possibilidades de entendimento acerca da maneira de se considerar o produto do trabalho do lexicógrafo. Buscamos então nossa fundamentação precisamente na disciplina que se ocupa de forma direta com o texto, a Linguística de Texto (LT). Já se consideraria de imediato que é nesse âmbito dos estudos exclusivos do texto que encontraríamos a resposta indubitável ao nosso questionamento. Por conseguinte, faz-se necessário esmiuçar o entendimento de texto nessa perspectiva. 
Nossa reflexão toma como ponto de partida o conceito de texto $\mathrm{to}_{L}$ seguido de explicitações acerca de condições para que um texto seja considerado, de fato, um texto. Após, teceremos considerações sobre os gêneros de texto, procedemos simultaneamente, e de forma breve, à análise de verbetes de alguns tipos de dicionários, na tentativa de verificarmos como se constituem e de que modo se aproximam das considerações teóricas sobre texto. Finalmente, apresentamos nossas reflexões conclusivas, as quais procurarão responder à pergunta proposta neste estudo.

\section{Sobre o conceito de texto}

O tratamento lexicográfico permite ao usuário do dicionário, falante da língua, conhecer mais da sua realidade linguística, facilita que ele possa estabelecer relações entre os significados e o uso de vocábulos específicos no dia a dia, quando inserido no processo comunicativo.

Tomando-se o verbete como exemplo, o qual é elemento do corpo do dicionário, que apresenta acepções, apresenta exemplos, perguntamo-nos se poderá constituir um texto. Questionamo-nos se teorias do texto preveem tal forma como um possível texto. No caso de não ser possível considerar-se texto, pergunta-se a que princípios sobre a constituição do texto a forma verbete não corresponderia. Restaria averiguar se o dicionário poderia então ser considerado um tipo específico de texto. Como já afirmamos anteriormente, se dicionário é "livro", é também texto, mesmo que constitua texto específico.

A constituição dos textos, o seu modo de funcionamento, os processos implicados nas tarefas de compreensão e de produção do texto são elementos de investigação da Linguística de Texto, bem como a determinação de critérios para a constituição de texto. Tais atribuições, no entanto, não se limitam à esfera do texto, extrapolam-no indo à análise do contexto, das condições de sua produção e recepção, condições externas ao texto.

De modo geral, segundo Lewandowsky (1975, s.v. Text), o conceito de texto pode ser tratado em diferentes perspectivas: a) como linguagem intuitivo-cotidiana - língua como expressão, em seu nível mais complexo; b) como fundamentado genericamente - signos linguísticos originários; c) levando em 
consideração elementos internos ao texto e à língua - sequência coerente de frases, contendo correferentes em comum; d) levando em consideração elementos externos ao texto e à língua - uma sequência de elementos linguísticos falados e escritos, os quais são indicadores de texto com base geralmente em critérios extralinguísticos; e) como orientado pelo uso destacado da língua - representações de uso do sistema linguístico, uso da língua em situação comunicativa; f) com uma perspectiva comunicativo-pragmática - unidade fechada da língua, formada intencionalmente, formada segundo as regras da gramática.

As perspectivas apontadas exigem que texto não possa ser considerado aleatoriamente. Ele dependerá de um ou de outro princípio para garantir seu reconhecimento como tal, ou seja, a fim de que possa ser entendido como texto, conforme atenda ou a um ou a outro critério, sob pena de não ser aceito como texto quando esta expectativa não for correspondida. Logo, as ênfases adotadas definirão caminhos teóricos sobre o texto.

O conceito de texto insere-se, pois, em estudos bem diferenciados, dependendo do objeto determinado de estudo de cada um deles. Em LT, entende-se texto de forma bem específica, distinta daquela considerada em outros domínios tanto da micro quanto da macrolinguística como, por exemplo, na Análise de Discurso ou na Pragmática. Priorizando o extralinguístico, a Pragmática estuda os significados linguísticos determinados não exclusivamente pelo sentido das frases, das proposições, mas pelo contexto do discurso e da situação; enquanto a Análise do Discurso preconiza texto como o produto da atividade do discurso, sendo o texto uma construção que contém os meios para análise. A LT é também distinta da análise literária, da retórica, da estilística (MARCUSCHI, 2012, p. 17). Assim, aspectos que garantem ênfase em determinadas disciplinas, em LT configuram-se também como essenciais somados ainda a outros aspectos.

Como se trata de um caminho teórico essencialmente para o estudo de texto, poder-se-ia inferir que se trata da possibilidade de se encontrarem conceitos definitivos na própria LT. No entanto, embora muito se tenha tratado acerca da conceitualização de texto nos inícios dos estudos europeus da LT, não se encontra um conceito único, definitivo, representativo de todos os autores voltados à LT. 
Assim, já desde os inícios dos estudos neste campo, em suas diferentes fases (cf. KOCH, 1997) autores como Petöfi, Schmidt, Halliday e Hasan, por exemplo, até mesmo Weinrich apontavam para determinados pré-requisitos inerentes à constituição de um texto em sua complexidade como condições para a sua estruturação.

Desta forma, para Petöfi (1972, p.31, apud MARCUSCHI, 2012, p. 26) “Uma sequência de elementos linguísticos escritos ou falados organizada como um todo, com base em algum critério qualquer (geralmente extralinguístico), resulta num texto". (grifo nosso).

Em outra perspectiva, na perspectiva do uso, já para Halliday e Hasan (1976, p.2) texto é "uma unidade em uso. Não é uma unidade gramatical, tal como uma frase ou uma sentença; e não é definida por sua extensão. (...) Um texto é, melhor dizendo, uma unidade semântica: não uma unidade de forma e sim de sentido". (apud MARCUSCHI, 2012, p.28) (grifo nosso).

Considerando a linearidade dos signos linguísticos, no entender de Weinrich (1976, p.186-7) texto é "uma sequência ordenada de signos linguísticos entre duas interrupções comunicativas importantes" (apud MARCUSCHI, 2012, p.25) (grifo nosso).

E, finalmente, tomando definições de texto com critérios temáticos e transcendentes ao texto, para Dijk (1978 e 1977) texto "é uma estrutura superficial governada por uma estrutura semântica profunda motivada", ou seja, "um conjunto ordenado de sentenças da estrutura profunda“. (apud MARCUSCHI, 2012, p.27) (grifo nosso).

Em perspectivas destacadas atualmente, as concepções abrem espaço a novas possibilidades de entendimento para texto, priorizando-se a comunicação, por exemplo, em detrimento da forma.

É o que se pode verificar em relação à noção de sentido, já destacada por Coseriu (1981, p. 51) ao denominar a LT como a Linguística do sentido, apresentando-nos texto em perspectiva distinta daquela dos anos 70, já que não necessariamente era definida pelas mesmas pretensões teóricas (cf. LAMAS, 2010).

Lamas (2010, p. 161), em esquema adaptado da versão em italiano, apresenta os dois conceitos ligados esquematicamente. $\mathrm{O}$ texto entendido como nível último da linguagem é um momento necessário do falar e o texto entendido como 
nível de organização gramatical de um idioma não o é. O autor explica que, para Coseriu, o nível dos elementos mínimos e o da oração são apenas racionalmente necessários, pois o texto "sendo reconhecido como unidade gramatical", implicaria o saber elocucional, o idiomático e, finalmente, o expressivo.

Compreendemos, portanto, o sentido como o conteúdo específico do texto, nas palavras do autor, dando-se a conhecer pelos então instrumentos ou significantes: as normas dos saberes ilocucional e idiomático.

\section{Sobre as condições para texto}

Marcuschi (2012, p. 22) apresenta critérios para se considerar um texto, os quais se distinguem entre critérios internos ao texto (olhando-o do ponto de vista imanente ao sistema linguístico) e critérios temáticos ou transcendentais ao sistema (considerando o texto como uma unidade de uso ou unidade comunicativa). Aspectos observáveis na produção, construção e recepção de textos são apresentados por Marcuschi (2012, p. 37), com base em Beaugrande e Dressler (1997) e outros, constituindo passos para sua sistematização geral, denominados como categorias textuais: "Assim chamo de categorias funcionais às categorias com que abordo o texto. Pois elas são funções que o texto vai cumprindo como entidade atual concreta e situacional e não como sistema abstrato" (MARCUSCHI, 2012, p. 36). O seu esquema de categorias textuais constitui-se de: a)Fatores de contextualização (localização, data, elementos gráficos), de conexões conceituais cognitivas (relações lógicas - como pressupostos e inferências, e modelos cognitivos globais - frames e macroestruturas); b) fatores de conexões sequenciais no texto (substituidores - como paráfrases; sequenciadores - como tema/rema, e moduladores - como modalidade); c) fatores de conexão de ações - como intertextualidade.

A funcionalidade subjacente ao esquema de Marcuschi (2012) permite-nos a aplicação à análise dos dicionários. Verifiquemos a seguir algumas das categorias em relação ao nosso objeto de estudo, o dicionário.

O conceito de dicionário, em Lewandowsky (1975, s.v. Wörterbuch), menciona justamente fatores de conexões sequenciais (possibilidade sintagmática de combinações) e fatores de conexões conceituais cognitivas do esquema proposto (possi- 
bilidades de seu uso). Estão contemplados os eixos das combinações, como por exemplo, os sequenciadores; e os modelos cognitivos globais, exemplificados pelos rituais.

Nossa análise voltada aos dicionários considera os critérios de textualidade de Beaugrande e Dressler (1997), isto é, o conjunto de condições para que um texto seja um texto, classificando-os conforme sua especificidade.

\subsection{Dois critérios de tipo linguístico: coesão e coerência}

Coesão (Sintaxe) - situa-se no nível local do texto. Diz respeito às sequências oracionais que, compondo a superfície textual, estão interconectadas através de relações gramaticais como a repetição, formas pronominais, a correferência, a elisão ou a conexão. Os elementos coesivos podem ser localizados, apontados no nível local do texto. Exemplo:

Figura 1 - MiAu (1993)

embaixador $(\hat{o}) \mathrm{sm}$. 1. A categoria mais alta de representante diplomático, e título de quem a ocupa(...)

MiAu (1993, s.v.)

A coesão no verbete embaixador (Fig. 1 - MiAu (1999, s.v.)) se dá em função de uma especificidade do tipo de texto que é o dicionário, já que um verbete é uma equação, que se lê da seguinte maneira: "dizer embaixador equivale a dizer a categoria mais alta de representante diplomático"; além disso, na segunda parte da paráfrase, há uma relação de correferência explícita (que а осира = a categoria). No entanto, classes de dicionários, como o etimológico (Fig. 2) e o de ideias afins / analógico ${ }^{15}$ (Fig. 3) apresentam os verbetes estruturados a partir de sintagmas, aparentemente isolados, sem contexto (sem frases estruturadas conforme as normas da língua).

15 Na literatura não está suficientemente estudada a diferença estrutural entre um dicionário de ideias afins e um dicionário analógico. $\mathrm{Na}$ carência de uma univocidade terminológica, preferiu-se usar uma expressão que abrangesse as duas designações.
Figura 2 - DEtPort (1996)

canção - sf. 'composição musical para ser cantada' XIII. Do lat. cantioonis// cancionEIRO XV// cançonETA / chanso-1873 / adaptação do fr. Chansonette

DEtPort (1996, s.v. canção) 
Figura 3 - Dicionário onomasiológico (dicionário de ideias afins, dicionário analógico)

\begin{tabular}{|cccc|}
\hline $\begin{array}{c}\text { IMPALPABILIDADE } \\
\text { Substantivos }\end{array}$ & $\begin{array}{c}\text { (insensibilidade tátil) } \\
\text { Adormecimento } \\
\text { Verbos }\end{array}$ & Entorpecimento & Imperceptibilidade \\
sensibilidade tátil & & \\
Adjetivos & Insensivel & Intátil & Impalpável \\
\hline
\end{tabular}

DIdAf (s.d. s.v. impalpabilidade)

No entanto, há uma relação estabelecida, na medida em que a sequência das palavras permite a construção do sentido do "texto" que se lê. Em outras palavras, a coesão do texto poderá parecer que não ocorre, já que as palavras não estão em ordem sequencial, unidas por conectores, por exemplo. $\mathrm{O}$ leitor, no entanto, imbuído da sua intenção de consulta à obra, encontra resposta, estabelecendo consequentemente o sentido na disposição das palavras do modo como se apresentam, resgatando a essência, o sentido do texto.

Coesão - dá-se quando os conceitos estão interconectados através de relações de natureza diversa, como causalidade, adversidade, proporcionalidade. Já a coerência, distinguindo-se da coesão, dá-se no nível global do texto, não se podendo apontá-la ou localizá-la diretamente. Exige esforço do leitor, por exemplo, no reconhecimento de pressupostos e inferências. O dicionário de citações é um exemplo do cumprimento do critério da coerência.

Figura 4 - ProvMax (1999)

Au jour le jour - Dia a dia. Viver diariamente com magros recursos. Gastar tudo o que se tem sem preocupações com a economia.

(...)

Aut Caesar, aut nihil - Ou Imperador (César) ou nada. Divisa atribuída a César Bórgia e que pode servir a todos os ambiciosos.

(...)

High fidelity - Alta fidelidade, em inglês. Alta qualidade e pureza de som obtida em aparelhos eletrônicos. (...)

Quand même - Mesmo assim, em francês. Apesar dos pesares, em qualquer hipótese.

$$
\text { ProvMax (1999, s.vs.) }
$$


Os verbetes acima (Fig. 4) são de natureza bilíngue, pois cada verbete apresenta duas línguas particulares, uma exercendo a função da língua fonte (língua estrangeira) e a outra, da língua alvo, no caso a língua portuguesa. Poder-se-ia concluir que os "textos" prováveis desses tipos de dicionários não existem, já que fogem à regra da consideração de um único idioma, de uma língua particular, restando o entendimento de que são incoerentes. Mas o conhecimento de outros textos já lidos, já conhecidos do leitor, portanto, permitem entendê-lo, já que o conteúdo é reconhecido justamente pelo conhecimento de textos já lidos. Assim a relação tema/rema também se dá, isto é, o conhecido, seguido do desconhecido. Desta forma, tais tipos de dicionários poderão não corresponder a todos os critérios de textualidade, mas apresentam um deles, o qual permite a construção do sentido do texto.

Alguns linguistas não distinguem entre coesão e coerência, entre um conceito e outro, considerando coesão e coerência uma unidade. Outros consideram as diferenças específicas, distinguindo claramente até que ponto se pode verificar a coesão, o mesmo se repetindo em relação à coerência. Cremos que, conforme Coseriu (1981), há texto, quando o sentido é resgatado.

\subsection{Dois critérios psicolinguísticos: intencionalidade e aceitabilidade}

\section{Intencionalidade}

Consiste em que a organização coesiva e coerente do texto, seguindo um plano dirigido, faça o cumprimento de uma meta, habitualmente extralinguística. Aceitabilidade - manifesta-se, quando um receptor reconhece que uma sequência de enunciados constitui um texto coeso, coerente e intencionado, porque o que comunica, a seu juízo, é relevante, como, por exemplo, s.v. sonhos em DMitGr (2008) (Fig. 5).

Figura 5 - DMitGr (2008)

Sonhos - Eram filhos do sono, e inumeráveis como as areias do mar. $O$ principal entre eles foi Morfeu, que somente habitava os palácios. Os outros, representados com asas negras de morcego, misturavam-se à multidão e ora eram assustadores, ora agradáveis. 
O verbete acima, constituído de um texto elaborado, corresponde a todos os critérios aqui tratados, não deixa dúvidas quanto ao texto construído conforme as condições para que um texto seja de fato considerado texto.

6.3. Dois critérios sociolinguísticos: situacionalidade e intertextualidade

\section{Situacionalidade}

Refere-se a fatores que fazem com que um texto seja pertinente em um determinado contexto de recepção.

Figura 6 - DCe (2006)

\section{Marromeno - Mais ou menos (...)}

Onde tu vais passar...? Cearense tem o vírus da migração, não pode ouvir falar em feriado que já corre para arrumar as malas. Na semana que antecede um feriadão, a pergunta mais ouvida entre amigos, parentes $e$ aderentes, é sobre o destino de cada um. "Onde tu vai passar a Semana Santa?" "Onde tu vai passar o São João"? E por aí vai.

DCe (2008, s.v.)

A compreensão dos verbetes acima (Fig. 6) é possível com o conhecimento do contexto específico de seu uso, isto é, na região nordeste do país.

\section{Intertextualidade}

Refere-se ao fato de que a interpretação de um texto depende do conhecimento de textos anteriores. Nos dicionários de discurso repetido, esse princípio é aplicado.

Figura 7 - IdRew (1993)

(jmdm.) unter die Haut gehen (umg). (jmdn.) erschüttern; (jmdn.) innerlich aufwühlen. "Ich denke immer noch an den Dokumentarfilm über die Hungersnot in einigen afrikanischen Ländern. Das waren Aufnahmen, die unter die Haut gingen"16

$$
\text { IdRew (1993, s.v.) }
$$

16 [Sempre lembro do documentário sobre a fome em alguns países africanos. Foram imagens que emocionaram]
Os critérios situacionalidade e intertextualidade são especialmente observados em verbetes de dicionários de expressões idiomáticas (Fig. 7), pois a compreensão do seu conteúdo 
depende do conhecimento situacional e intertextual do leitor. $\mathrm{O}$ uso adequado das expressões requer tais conhecimentos, sob pena de o falante poder incorrer em constrangimentos em situações de comunicação devido à incompreensão do significado das expressões. Não basta conhecer o significado literal, denotativo das palavras, já que formam expressões em função do seu sentido conotativo.

6.4. Um critério computacional: informatividade

Figura 8 - DtermLit (2010)

CASTICISMO - Latim casta (m), raça pura, sem mistura. A palavra casticismo é praticamente sinônimo de purismo (Fig. 8). É uma linguagem que rejeita neologismos e todas as palavras ou frases que não se apoiam na tradição literária, significando ameaça à sua integridade.

DTermLit (2010, s.v. casticismo)

A informatividade é um fator da novidade que motiva o interesse pela recepção de um texto. Nenhum texto é totalmente novo, assim como nenhum texto deveria ser totalmente conhecido, isto é, sem nova informação. É, pois, uma exigência do interlocutor que a novidade esteja instaurada no novo texto, evitando rejeição da proposta enunciativa do emissor, caso não corresponda.

Concluímos, portanto, que os verbetes de dicionários permitem aos leitores encontrar o sentido dos textos, seja pela estruturação do texto conforme os critérios de textualidade, seja pela compensação da ausência de algum critério, pelo resgate do sentido de algum modo, dependendo da natureza do dicionário. Assim, parece que os verbetes não atendem exatamente a todos os critérios de textualidade na sua construção, mas permitem, contudo, o resgate do sentido, a essência do texto.

\section{Sobre os gêneros de texto e o entendimento de dicionário como texto}

Os dicionários específicos parecem, por conseguinte, poder constituir um gênero específico de texto, conforme os princípios da Linguística de Texto, já que atendem a funções determinadas da linguagem, as quais se concretizam nos diferentes tipos de dicionários. 
Dos princípios de textualidade às funções predominantes para um texto, a essência está na intenção comunicativa, na ideia especificada, no significado reconhecido pelo falante, pelo interessado. É o que ocorre na relação consulente / dicionário.

O dicionário, portanto, sendo entendido como um texto, constitui necessariamente um tipo, manifestado em muitos gêneros (isto é, cada classe específica de dicionários, tais como o dicionário de sinônimos, o dicionário da rima, etc.).

A ideia de se conceber dicionário como texto pode sustentar-se principalmente na questão do gênero. E é nessa concepção que centramos nossa reflexão acerca de dicionário como texto, já que entendemos as diferentes classes de dicionários como diferentes gêneros do texto dicionário.

Ao estudarmos os preceitos da Linguística de Texto, concentramo-nos, por exemplo, nos fatores que determinam sua constituição. Nas palavras de Marcuschi (2012, p.37-8) retomamos os fatores: conexão conceitual-cognitiva, conexão de ações, conexão sequencial e contextualizadores, os quais juntos constroem o complexo textual. Tais aspectos dão conta da abrangência de elementos para a incorporação de um texto. Assim, quando nos atemos à estrutura do texto, por exemplo, estamos dando atenção à construção coesa e coerente do texto. As preocupações com a forma, denotadas nas sequências construídas com coesão, podem ser decisivas para que se dê a coerência do texto, logo a construção do seu sentido.

Vimos em nossa exposição até aqui, portanto, que um aglomerado de palavras por si só não terá função, portanto não terá sentido. A função comunicativa é que vale para o falante, para o autor, para o usuário, para aquele que deseja expressar algo. Ejustamente tendo em vista a função pragmática do texto é que poderemos abrir espaço para inúmeros textos, aos quais correspondem as inúmeras funções que podem desempenhar, servindo como meio de expressão na apresentação de ideias com sentido. Desse modo é que podemos entender os diferentes gêneros de texto, cada um atendendo a funções comunicativas específicas em contextos determinados.

Dicionários desempenham funções em diferentes situações de comunicação, logo se configuram, atualizam-se empiricamente. Seguindo o pensamento de Marcuschi (2012), os 
gêneros textuais não se limitarão a questões de língua ou de estrutura de texto, irão se concentrar é nas funções (comunicativas, cognitivas e institucionais) que virão a desempenhar no contexto social. O usuário do dicionário, portanto, será quem decidirá pelo uso de uma ou outra forma de dicionário, conforme a sua função na situação de comunicação, na sua "prática sócio-discursiva". (MARCUSCHI, 2012). Se pensarmos em sons, imagens e formas, por exemplo, estaremos considerando dicionários impressos e dicionários virtuais, os quais contemplam o hibridismo citado pelo autor, dando-se a integração entre os "diversos tipos de semioses". Os muitos tipos de dicionários cumprem esse papel integrativo. Considerando a definição em si, a qual se apresenta sob mais de uma forma, mais de um tipo (HERBST e KLOTZ, 2003, p. 32).

Os gêneros associam-se ao uso e não à forma, dependendo dos objetivos do usuário do dicionário neste caso, dependendo do seu perfil.

\section{Considerações finais}

Em primeiro lugar, é necessário salientar que o ato de interrogação inicial desse trabalho partiu da premissa de que o dicionário pode ser considerado um texto, de modo que a argumentação apresentada teve como objetivo confirmar essa hipótese.

Em relação ao arcabouço teórico empregado, é fundamental salientar, primeiramente, que as diferentes classes de dicionários constituem gêneros, e, em segundo lugar, ressaltar que a obra lexicográfica possui propriedades (textuais) que permitem reconhecê-la como um tipo de texto. Em terceiro lugar, cumpre enfatizar que uma taxonomia de obras lexicográficas representa um número de gêneros textuais que se depreende de um tipo de texto chamado dicionário.

Finalmente, cabe assinalar que o presente trabalho almeja iniciar uma discussão sobre o status epistemológico do dicionário à luz da linguística de texto. 


\section{DICIONÁRIOS CITADOS}

DCe (2008). GARCÍA, T. Dicionário do Ceará. Palavras típicas, expressões pitorescas e como usá-las. Fortaleza: Edições Livro Técnico.

DEtPort (1996). CUNHA, A. G. da. Dicionário Etimológico da Lingua Portuguesa. Rio de Janeiro: Nova Fronteira.

DIdAf (s.d.). SARGENTIM, H. Dicionário de idéias afins. São Paulo: Instituto Brasileiro de Edições Pedagógicas.

DMitGr (2008). GUIMARÃES, R. Dicionário de Mitologia grega. São Paulo: Cultrix.

DTermLit (2010). MOISÉS, M. Dicionário de termos literários. São Paulo: Cultrix.

DuBldWtb (1995). Duden Oxford Bildwörterbuch Deutsch / Spanisch. Mannheim: Bibliographisches Institut.

Hou (2009). HOUAISS, A. Dicionário Houaiss da Língua Portuguesa. Rio de Janeiro: Objetiva.

IdRew (1993). HERZOG, A; MICHEL, A; RIEDEL, H. Idiomatische Redewendungen Von A - Z. Ein Übungsbuch für Anfänger und Fortgeschrittene. Berlin / München / Wien / Zürich / New York: Langenscheidt / Verlag Enzyklopädie.

MiAu (1993). FERREIRA, Aurélio Buarque de Holanda. Mini dicionário Aurélio da língua portuguesa. Rio de Janeiro: Nova Fronteira.

OhneWtb (1999). Langenscheidts OhneWörterBuch. Berlin: Langenscheidt.

ProvMax (1999). SOUZA, J. R. (Org.). Provérbios \& Máximas. Coletânea de provérbios, máximas, sentenças e aforismos em 7 idiomas. Rio de Janeiro: Lucerna.

ThEssPort (2013). AZEVEDO, F. F. dos S. Thesaurus Essencial. Dicionário analógico. Rio de Janeiro: Lexikon.

VWtbPD (2010). Visuelles Wörterbuch Portugiesisch / Deutsch. München: Dorling Kindersley.

ZWtb (2014). Zeigewörterbuch. Einfach auf alles zeigen. Stuttgart: Pons. 


\section{REFERÊNCIAS BIBLIOGRÁFICAS}

BALDINGER, K. Teoría semántica. Hacia una semántica moderna. Madrid: Alcalá, 1977.

DRESSLER, W.U.; BEAUGRANDRE, R. Introducción a la lingüística del texto. Barcelo BUGUEÑO MIRANDA, F. Da classificação de obras lexicográficas e seus problemas: proposta de uma taxonomia. Alfa. São Paulo, v. 58, p. 215-231, 2014.

BUGUEÑO MIRANDA, F. Balanço e perspectivas da lexicografia. Cadernos de Tradução. Florianópolis, v. 2, p. 1537, 2013a.

BUGUEÑO MIRANDA, F. Resenha a Visuelles Wörterbuch Portugiesisch / Deutsch (2010). Pandaemonium Germanicum. São Paulo, v. 16/21, p. 232-235, 2013 b.

BUGUEÑO MIRANDA, F. Para uma taxonomia de paráfrases explanatórias. Alfa. São Paulo, v. 53, p. 243-260, 2009.

BUGUEÑO MIRANDA, F. Panorama da lexicografia alemã. Contingentia. Porto Alegre, v. 3/22. p. 89-110, 2008. Disponível em: http://www.seer.ufrgs.br/index.php/contingentia/article/ view/6508/4241. Acessado em: 21.08.2014.

BUGUEÑO MIRANDA, F. O que é macroestrutura no dicionário de lingua?. In: ISQUERDO, A. N.; ALVES, I. M. (Org.). As ciências do Léxico: Lexicologia, lexicografia e terminologia. São Paulo: Humanitas, 2007, v. III, p. 261-272.

BUGUEÑO MIRANDA, F.; FARIAS, V. Los subsidios de tres teorías semánticas para la generación de definiciones lexicográficas. Revista de Filología de la Universidad de la Laguna. La Laguna, v. 31, p. 19-34, 2013.

BUGUEÑO MIRANDA, F.; ZANATTA, F. Problemas medioestruturais em dicionários semasiológicos do português. Lusorama. Frankfurt am Main, v. 83-84, p. 80-97, 2010.

na: Ariel, 1997.

BLACKBURN, S. Dicionário Oxford de Filosofia. Rio de Janeiro: Jorge Zahar, 1997.

COSERIU, E. Textlinguistik. Eine Einführung. Tübingen: Narr, 1981. DIONÍSIO, A. P.; MACHADO, A. R.; BEZERRA, M. A. (Orgs.). Gêneros textuais E ensino. Rio de Janeiro: Lucerna, 2005. 
FORNARI, M. Concepção e Desenho do Front Matter do Dicionário de Falsos Amigos Espanhol - Português. Revista Voz das Letras. Contestado, v. 9, p. 1-15, 2008.

FRAWLER, W. The dictionary as a text. In: HARTMANN; R.R.K. (ed.). Lexicography. Critical concepts. London / New York: Routledge / Taylor and Francis, 2003, p. 231-248.

HARTMANN; Reinhardt; JAMES, Gregory. Dictionary of lexicography. London: Routledge, 2001.

HERBST, Th.; KLOTZ, M. Lexikographie. Paderborn / München / Wien / Zürich: Shöningh, 2003.

ISENBERG, H. Cuestiones fundamentales de tipología textual. In: BERNÁRDEZ, Enrique (comp.). Lingüística del texto. Madrid: Arco/Libros, 1987, p. 95-129.

KIRCHNER, F. et alii. Wörterbuch der philosophischen Begriffe. Hamburg: Felix Meiner, 2013.

KOCH, I. V. Linguística de Texto: retrospecto e perspectivas. Disponível em: http://seer.fclar.unesp.br/alfa/article/ viewFile/4012/3682. Acesso em: 20.09.14.

LAMAS, Ó. L. Linguagem e Discurso. Eugenio Coseriu. Tradução: Cecília Ines Erthal. Curitiba: Ed. UFPR, 2010.

LEWANDOWISKI, Th. Linguistisches Wörterbuch. Heidelberg / Wiesbaden: Quelle \& Meyer, 1994.

MARCUSCHI, L.A. Linguística de texto. O que é e como se faz. São Paulo: Parábola Editorial, 2012.

MLS (2010). GLÜCK, Helmut (Hrsg.). Metzler Lexikon Sprache. Stuttgart: Metzler.

REHFUS, W. (Hrsg.). Handwörterbuch Philosophie. Göttingen: Vandenhoeck \& Ruprecht, 2003.

WIEGAND, H. E. Components Parts and Structures of General Monolingual Dictionaries: A Survey. In: HAUSMANN, F. J.; REICHMANN, O.; WIEGAND, H. E.; ZGUSTA, L. (Hrsgn.). Wörterbücher. Dictionaries. Dictionnaires. Ein internationales Handbuch zur Lexikographie. Berlin / New York: de Gruyter, 1989, p. 328-360. 


\section{Abstract}

\section{Why a dictionary is a text?}

Dictionaries have the particularity of being similar to a book without, apparently, showing the same characteristics of other kinds of books, like scientific publications or novels. Supported by a linguistic theory, this paper aims at demonstrating that dictionaries are texts.

Keywords: dictionary, text linguistics; type; genre. 